\title{
Correlations between Impulsivity and Technical Performance in Handball Female Athletes
}

\author{
Guilherme M. Lage ${ }^{1}$, Lívia G. Gallo ${ }^{1}$, Gabriela J. M. Cassiano ${ }^{1}$, Ingrid L. B. Lobo ${ }^{1}$, \\ Marcus V. Vieira ${ }^{2}$, João V. Salgado ${ }^{3}$, Daniel Fuentes ${ }^{4}$, Leandro F. Malloy-Diniz ${ }^{5}$ \\ ${ }^{1}$ College of Health Sciences, Universidade FUMEC, Belo Horizonte, Brazil; \\ ${ }^{2}$ Helena Antipoff Fundation, Ibirité, Brazil; \\ ${ }^{3}$ Institute of Biological Sciences, Universidade Federal de Minas Gerais, Belo Horizonte, Brazil; \\ ${ }^{4}$ Psychiatry Institute, Universidade de São Paulo, Sao Paulo, Brazil; \\ ${ }^{5}$ Faculty of Philosophy and Human Sciences, Universidade Federal de Minas Gerais, Belo Horizonte, Brazil. \\ Email: menezeslage@gmail.com \\ Received July $13^{\text {th }}, 2011$; revised August $24^{\text {th }}, 2011$; accepted September $27^{\text {th }}, 2011$.
}

\begin{abstract}
A complex and dynamic environment where impulsivity probably interferes in the human behavior is the sport context. The aim of this exploratory study was to investigate the possible relationship between impulsivity and technical performance in handball athletes. Eleven junior female athletes on a handball team were submitted to a neuropsychological assessment of impulsivity using Conner's CPT-II and the Iowa Gambling Task. In 11 matches, participants' handball performance was analyzed. We adopted the resampling statistical approach to correlate the measures of technical performance with the neuropsychological measures. IGT net score was positively correlated with technical faults. Omission errors on the CPT-II were positively correlated with the number of fouls suffered, the number of fouls committed, and the number of offensive fouls. Commission errors on the CPT-II were negatively correlated with rebounds with defense ball possession. Our results support the idea of relationships between impulsivity and technical performance in specific match situations.
\end{abstract}

Keywords: Impulsivity, Sports, Handball, Motor Behavior, Attention, Decision Making, Response Inhibition

\section{Introduction}

Impulsivity is a behavioral pattern characterized by several types of manifestations. For instance, Barratt (Patton, Stanford, \& Barrat, 1995) proposed the existence of three classes of impulsivity: motor (acting without thinking), attentional (lack of focus on the task at hand), and non-planning (focus on the present without accounting for the consequences of the future outcomes).

The impulsive behavior is a core symptom in a large number of psychiatric disorders but, nonetheless, there is also a growing interest in the role of impulsivity among healthy populations engaging in different activities (Stanford, Mathias, Dougherty, Lake, Anderson, \& Patton, 2009). For example, a complex and dynamic environment where impulsiveness probably interferes in the human behavior is the sportive context. Previous research in this area has focused on demonstrating the relationship between impulsivity and the involvement in particular types of sports. Svebak and Kerr (1989), for example, compared the impulsiveness of athletes involved in sports defined as "endurance sports" (i.e., those involving sustained activity) and "explosive sports" (i.e., those involve short, intense bursts of activity). They found that athletes who engaged in explosive sports (e.g., football) scored higher on impulsivity measures than endurance participants (e.g., marathon runners).

Impulsivity may be an important factor in motor performance interference in open-skill sports (e.g., soccer, basketball and handball). Due to constant changes in the environment (e.g., alterations in opponents positioning), the player is forced to inhibit pre-planned responses, anticipate actions and coordinate corporal segments based on the complex and dynamic flow of sensorial information. Previous studies using motor laboratory tasks have shown that motor control is affected by the degree of the subject's impulsivity (Enticott, Ogloff, \& Bradshaw, 2006; Lemke, Fischer, Wendorff, Fritzer, Rupp, \& Tetzlaff, 2005). For instance, healthy individuals with higher impulsivity scores present shorter relative time to achieve the peak velocity than the low-impulsives in manual aiming movements (Lemke et al., 2005). In addition, high-impulsive subjects tend to inhibit their responses at a slower pace than low-impulsive subjects (Lijffit, Bekker, Quik, Bakker, Kenemans, \& Verbaten, 2004). Highimpulsive subjects also present higher reaction time than lowimpulsives in conditions of low compatibility stimulus-response (Expósito \& AndrésPueyo, 1997) and are less accurate than low-impulsives in tapping at a specified rate (Barrat, 1981). In spite of some controversial findings (cf. Dickman, 1993), the general pattern over the course of these studies has indicated that high-impulsive subjects are faster in their responses but less accurate than their less impulsive counterparts (Lage, Malloy-Diniz, Neves, Moraes, \& Corrêa, in press).

Although generally viewed as counterproductive (Stanford et al., 2009), it is possible that impulsivity had a positive role on motor behavior in some specific circumstances. This may be true in cases in which there is limited time available to: 1) recognize the opponent's action; 2) process a decision; and 3) organize the motor system to initiate a response. In such situations, it is probable that some degree of impulsivity helps the player to achieve his/her goal successfully. An explanation for this hypothesis might be based on the concept of functional impulsivity characterized by a tendency or ability to think, act and speak rapidly (Dickman, 1990, Reeve, 2007). Recently, Lage et al. (in press) found that in situations in which the temporal and spatial demands to the motor system were high, the impulsivity had a functional, adaptive effect on manual motor control. 
Although several evidences suggest an influence of impulsivity on motor control, to our knowledge, there are no studies investigating this relation in the context of competitive sports. Therefore, we aimed to investigate the relationships between different impulsivity dimensions and technical performance in an open-skill sport. Handball was chosen because it is a fast and dynamic game that is played in a confined area where a high degree of temporal and spatial pressure is involved. The very intense physical contact among players often creates moments of forceful behaviors, and the close proximity of coaches, officials and spectators to the court may represent an increased psychological demand.

Although our approach was mainly exploratory, on the basis of previous evidence found in laboratory studies, an association between impulsivity dimensions and technical performance was predicted. In match situations in which both speed and accuracy are categorically involved (e.g., when a shot on goal is taken), motor impulsivity should be a factor of possible interference. In match conditions that require high decisional demand (e.g., when the player holds the ball and has a second or two to decide what to do next), non-planning impulsivity may be related to the quality of motor response. In situations in which the attentional demands are high (e.g., a direct confrontation with the opponent), attentional impulsivity might be related to the player's level of success.

\section{Methods}

\section{Participants}

Twenty-two junior female athletes (between 17 and 18 years of age; mean age $=17.45 \pm 0.5$ years) from a three-time state champion handball team were invited to participate in this study. All of them were court players. Seven players decided to not participate, resulting in a sample of fifteen athletes. On average, participants had $6 \pm 1.8$ years of handballs experience. The local ethics review committee approved the study protocol. All participants and their parents (only for the 17-year-old participants) signed informed consent forms before participating in this study.

\section{Instruments}

The neuropsychological assessment has been described elsewhere (see in Malloy-Diniz et al., 2007). Briefly, we used Conner's Continuous Performance Task (CPT-II; omission and commission errors as measures of attentional and motor impulsivity) and the Iowa Gambling Task (IGT; the net score was used as a measure of non-planning, decision-making, -related impulsivity). Unlike CPT-II scores, high scores on the IGT indicate a low level of impulsivity (Lage, Malloy-Diniz, Matos, Bastos, Abrantes, \& Corrêa, 2010).

Handball Technical Performance Evaluation. To scrutinize the technical performance of the 15 court players, some parameters of a handball scout were used (Vieira, Greco, \& Chagas, 1990). The performance parameters investigated were divided into technical faults, throwing and other measures.

The technical faults of each player were analyzed based on the number of times any of the following occurred: 1) passing error; 2) reception error; 3 ) touching the ball with the foot; 4) double dribble; 5) loss of ball possession; 6) entering the goal area; 7) carrying the ball for more than three steps; 8) holding the ball for more than three seconds; and 9) offensive foul. The technical performance related to the throwing was ana- lyzed through the number of: 1) shots scored (goals); 2) shots missed (ball was out of the court or ball hit the goalpost or crossbar); 3) shots caught by the goalkeeper; 4) shots that resulted in rebounds with defense ball possession (goalkeeper rebounded and ball possession was returned to the defense); 5) shots that resulted in rebounds with attack ball possession (goalkeeper rebounded and the ball possession stayed with the attack); 6) shots blocked with defense ball possession (shot blocked and the defense stayed with the ball possession); and 7) shots blocked with attack ball possession (shot blocked and the ball returned to the attack players). Other performance measures analyzed were: 1) gaining possession of the ball ("stolen" the ball of opponent); 2) passive play; 3) fouls committed; and 4) fouls suffered. In each match, all of these technical aspects were analyzed for each player throughout the handball scout.

\section{Procedure}

Eleven matches in the regional championship (during the first semester of 2007) were analyzed. During the same period (first semester of 2007, before the championship), the CPT-II and IGT were administered to all players. Two trained physical education professionals were responsible for watching and filling the scouts during the matches. A third experimenter filmed the matches in case of doubt in the posterior analyses. Two trained neuropsychologists administered the neuropsychological tests (tests were applied individually in a quiet room. See detailed procedures in Malloy-Diniz, 2007). The order of CPT-II and IGT application was randomized among participants. The entire procedure was blinded since the neuronpsychologists did not watch the matches and the physical education professionals did not have access to neuropsychological results.

\section{Analyses}

Before the contest, we conducted a pilot study that consisted of the analysis of three handball matches. The purpose of the study was to analyze the coefficient of concordance among the three physical education professionals. Kendall's $W$ test indicated a significant degree of concordance $(W=.9193, \mathrm{p}<.0001)$ on the filling of the scout.

After the championship, the match analysis showed that three players did not play any of the 11 matches. One athlete played for only a very short time during matches (mean of 11.25 minutes). Thus, we decide to exclude this player from the final analysis. Therefore, the final sample was composed of 11 athletes who played a mean of $7.58(\mathrm{SD}=2.7)$ matches with a mean time on court of $33.24(\mathrm{SD}=10.6)$ minutes.

Due to the small sample size of this study we adopted the resampling statistical approach (Stergiou, 2004), more specifically, a correlation with random data permutation (see the procedures in Edginton \& Onghena, 2007: p.178). We correlated the measures of technical performance (the mean for each player during the 11 matches) with the neuropsychological measures (scores obtained in each test). The number of resamples of the original data was equal to 1000 , and the level of significance adopted in all analyses was .05. The software used was RT4win (Edginton \& Onghena, 2007).

\section{Results}

Neuropsychological data of each player are presented in Ta- 
ble 1 .

Technical performance data of each player are presented in Table 2. The technical fault of "holding the ball for more than three seconds" was not analyzed because this variable was constant (zero) during all matches for all players.

\section{Correlations between Technical Faults and Neuropsychological Measures}

The correlations between technical faults and neuropsychological measures are shown in Table 3. A significant nega-

Table 1.

Neuropsychological data of each player.

\begin{tabular}{|c|c|c|c|c|c|c|c|c|c|c|c|}
\hline \multirow{2}{*}{ Neuropsychological data } & \multicolumn{11}{|c|}{ Players } \\
\hline & 1 & 2 & 3 & 4 & 5 & 6 & 7 & 8 & 9 & 10 & 11 \\
\hline $\mathrm{OE}$ & 12 & 7 & 13 & 12 & 11 & 5 & 17 & 16 & 15 & 6 & 8 \\
\hline $\mathrm{COE}$ & 35 & 7 & 21 & 11 & 18 & 21 & 11 & 21 & 26 & 3 & 17 \\
\hline
\end{tabular}

Note: Neuropsychological measures: $\mathrm{OE}=$ omission errors on the CPT-II; COE = commission errors on the CPT-II; Net Score $=$ total score on the IGT.

Table 2.

Technical performance data of each player.

\begin{tabular}{|c|c|c|c|c|c|c|c|c|c|c|c|}
\hline \multirow{2}{*}{ Performance measures } & \multicolumn{11}{|c|}{ Players } \\
\hline & 1 & 2 & 3 & 4 & 5 & 6 & 7 & 8 & 9 & 10 & 11 \\
\hline Matches & 4 & 11 & 10 & 5 & 4 & 11 & 4 & 8 & 10 & 10 & 6 \\
\hline MTC & 16.3 & 41.2 & 46.3 & 40.5 & 34.7 & 42.2 & 21.6 & 30.6 & 38.3 & 36.2 & 40.1 \\
\hline $\mathrm{RE}$ & 1 & 1 & 4 & 3 & 3 & 1 & 10 & 2 & 3 & 4 & 0 \\
\hline TBF & 0 & 0 & 2 & 1 & 1 & 1 & 3 & 0 & 1 & 2 & 2 \\
\hline DD & 0 & 0 & 3 & 1 & 2 & 0 & 1 & 0 & 0 & 0 & 0 \\
\hline LBP & 0 & 1 & 0 & 4 & 0 & 1 & 1 & 0 & 0 & 0 & 0 \\
\hline CBTS & 0 & 0 & 10 & 0 & 0 & 2 & 0 & 1 & 3 & 0 & 0 \\
\hline OF & 0 & 0 & 1 & 0 & 0 & 0 & 1 & 0 & 0 & 0 & 0 \\
\hline SS & 8 & 2 & 45 & 65 & 16 & 12 & 54 & 4 & 13 & 35 & 6 \\
\hline SM & 4 & 0 & 9 & 12 & 1 & 2 & 15 & 0 & 4 & 5 & 0 \\
\hline $\mathrm{SC}$ & 3 & 2 & 14 & 16 & 13 & 6 & 19 & 1 & 6 & 9 & 2 \\
\hline SRDP & 0 & 0 & 0 & 0 & 0 & 0 & 5 & 0 & 0 & 0 & 0 \\
\hline SRAP & 0 & 1 & 0 & 1 & 0 & 0 & 0 & 0 & 0 & 0 & 0 \\
\hline SBDP & 1 & 0 & 0 & 0 & 0 & 0 & 0 & 0 & 1 & 1 & 0 \\
\hline PASSIV & 0 & 0 & 0 & 0 & 1 & 0 & 0 & 0 & 0 & 0 & 0 \\
\hline $\mathrm{FC}$ & 17 & 6 & 60 & 35 & 13 & 7 & 42 & 2 & 17 & 28 & 6 \\
\hline FS & 24 & 7 & 52 & 19 & 24 & 7 & 37 & 6 & 16 & 27 & 9 \\
\hline
\end{tabular}

Note: Number of matches played $=$ Matches. Mean time on court (minutes) $=$ MTC. The technical performance measures: passing errors $(\mathrm{PE})$; reception errors $(\mathrm{RE})$; touching the ball with the foot (TBF); double dribble (DD); loss of ball possession (LBP); enter the goal area (EGA); carrying the ball for more than three steps (CBTS); offensive foul (OF); shots scored (SS); shots missed (SM); shots caught by the goalkeeper (SC); shots that result in rebounds with defense ball possession (SRDP); shots that result in rebounds with attack ball possession (SRAP); shots blocked with defense ball possession (SBPD); shots blocked with attack ball possession (SBAP); gaining possession of the ball (GPB); passive play (PASSIV); fouls committed (FC); and (4) fouls suffered (FS). 
Table 3.

Correlations between technical faults and neuropsychological measures.

\begin{tabular}{|c|c|c|c|c|c|c|c|c|c|}
\hline \multirow{2}{*}{ Impulsivity measures } & & \multicolumn{8}{|c|}{ Technical faults } \\
\hline & & PE & $\mathrm{RE}$ & TBF & DD & LBP & EGA & CBTS & $\mathrm{OF}$ \\
\hline \multirow[t]{2}{*}{$\mathrm{OE}$} & $r=$ & -.44 & .03 & -.47 & -.29 & .01 & .14 & .20 & $-.61 *$ \\
\hline & $p=$ & .18 & .92 & .14 & .38 & .95 & .65 & .57 & .04 \\
\hline \multirow[t]{2}{*}{$\mathrm{COE}$} & $r=$ & -.13 & .07 & -.37 & -.50 & .38 & -.39 & -.55 & -.18 \\
\hline & $p=$ & .69 & .83 & .24 & .13 & .25 & .22 & .08 & .53 \\
\hline \multirow[t]{2}{*}{ Net Score } & $r=$ & .11 & .28 & .04 & .28 & -.34 & $.63 *$ & $.69 *$ & $.64 *$ \\
\hline & $p=$ & .74 & .36 & .90 & .37 & .32 & .02 & .02 & .02 \\
\hline
\end{tabular}

Note: " significant correlation $(\mathrm{p} \leq .05)$. The technical performance measures: passing errors $(\mathrm{PE})$; reception errors $(\mathrm{RE})$; touching the ball with the foot $(\mathrm{TBF})$; double dribble (DD); loss of ball possession (LBP); enter the goal area (EGA); carrying the ball for more than three steps (CBTS); offensive foul (OF). Neuropsychological measures: omission errors on CPT-II (OE); commission errors on CPT-II (COE); total score from IGT (Netscore). The $r$ values refer to original data and the $p$ values refer to the 1,000 resampling.

tive correlation $(\mathrm{r}=-.61, \mathrm{p}=.04)$ was found between offensive fouls (OF) and omission errors (OE) on the CPT-II. In other words, the number of fouls made in attack was inversely correlated with the players' level of attentional impulsivity. Furthermore a positive correlation was found between the IGT net score and the following foul measures: 1) entering the goal area (EGA) $(\mathrm{r}=.63, \mathrm{p}=.02) ; 2)$ carrying the ball for more than three steps (CBTS) $(\mathrm{r}=.69, \mathrm{p}=.02)$; and 3$)$ offensive foul (OF) $(\mathrm{r}=.64, \mathrm{p}=.02)$. Since high IGT net scores indicate low levels of non-planning impulsivity, a lower level of this kind of impulsivity was related to a higher number of offensive fouls. Other correlations were not significant (Table 3).

\section{Correlations between Throwing Performance and Neuropsychological Measures}

The analysis of technical performance related to the throwing and neuropsychological measures (Table 4) showed a significant positive correlation between shots that resulted in rebounds with defense ball possession (SRDP) and commission errors (COE) on CPT-II $(\mathrm{r}=.67, \mathrm{p}=.03)$. This finding shows that higher levels of motor impulsivity were related to a higher number of balls defended by the goalkeeper that resulted in rebounds with defense ball possession. Other correlations were not significant (Table 4).

\section{Correlations between Other Performance Measures and Neuropsychological Measures}

Omission error scores on the CPT-II were negatively correlated with the following performance measures: 1) gaining possession of the ball (GPB) $(r=-.63, p=.03) ; 2)$ fouls committed (FC) $(r=-.63, p=.04)$; and 3) fouls suffered (FS) $(r=$ $-.63, p=.02$ ). In other words, higher levels of attentional impulsivity were related to fewer fouls (committed or suffered) and fewer "stolen" balls (represented by the gaining possession of the ball measure). Other correlations were not significant (Table 5).

\section{Discussion}

The aim of this exploratory study was to investigate the possible relationships between impulsivity dimensions and technical performance on an open-skill sport. To the best of our knowledge, this is the first study to investigate the possible relationship between impulsivity and this specific facet of sports - the technical skills. Three types of results were identified: non-planning impulsivity was positively correlated with measures related to technical faults; attentional impulsivity was positively correlated with measures related to fouls; motor impulsivity was negatively correlated with a measure of throwing: rebounds with defense ball possession. The magnitude of all significant correlations was moderate $(0.61-0.69)$.

Non-planning impulsivity, as measured on the IGT, was positively correlated with the following measures of technical faults: 1) entering the goal area; 2) carrying the ball for more than three steps; and 3) offensive foul measures. At first sight, these findings seem paradoxical because low non-planning impulsivity was correlated with a higher number of technical faults. It has been shown that non-planning impulsivity has a dysfunctional role in decision-making so that impulsive individuals make risky decisions. In doing so, they choose immediate rewards despite potential long-term negative consequences (Möller, Barrat, Dougherty, Schmitz, \& Swann, 2001). Decision-making consists of multiple operations, including option evaluation, actions and outcome monitoring. These operations involve slow, conscious and effortful reflections about possible consequences (Bechara \& Van der Linden, 2005). This is a remarkable feature in open-skill sports characterized by a high level of uncertainty that forces the player to use complex cognitive skills under temporal pressure (Ripoll, Kerlirzin, Stein, \& Reine, 1995). Hence, it is possible that players with low non-planning impulsivity emphasize the accuracy of motor responses, thereby causing a temporal cost in situations in which the speed of information processing is an essential feature. In other words, players with low non-planning impulsivity would have decreased technical performance in match situations in which they needed to think and respond quickly.

This assumption is corroborated by Dickman and Meyer (1988), who found a relationship between impulsivity and optimality of performance. High-impulsive subjects exhibited decreased performance when accuracy was rewarded more than speed, whereas low-impulsive subjects presented a disadvantage when speed was rewarded more than accuracy. In this sense, individuals at both extremes of the impulsivity continuum are at a disadvantage under specific circumstances. However, further studies are needed to confirm that functional impulsivity has a positive role in open-skill sports in which complex decision-making under temporal and/or spatial pressure is 
Table 4.

Correlations between performance in throwing and neuropsychological measures.

\begin{tabular}{|c|c|c|c|c|c|c|c|c|}
\hline \multirow{2}{*}{ Impulsivity measures } & & \multicolumn{7}{|c|}{ Measures of performance in throwing } \\
\hline & & SS & SM & $\mathrm{SC}$ & SRDP & SRAP & SBDP & SBAP \\
\hline \multirow[t]{2}{*}{$\mathrm{OE}$} & $r=$ & -.31 & -.57 & -.33 & .12 & -.49 & .18 & -.33 \\
\hline & $p=$ & .38 & .07 & .32 & .77 & .09 & .55 & .36 \\
\hline \multirow[t]{2}{*}{$\mathrm{COE}$} & $r=$ & -.14 & -.08 & -.28 & $.67^{*}$ & .13 & .22 & -.37 \\
\hline & $p=$ & .67 & .81 & .38 & .03 & .80 & .50 & .16 \\
\hline \multirow[t]{2}{*}{ Net Score } & $r=$ & -.08 & -.04 & -.02 & -.26 & .13 & -.14 & .72 \\
\hline & $p=$ & .81 & .98 & .92 & .35 & .53 & .65 & .08 \\
\hline
\end{tabular}

Note: * significant correlation $(\mathrm{p} \leq .05)$. technical performance measures: 1) shots scored (SS); 2) shots missed (SM); 3) shots caught by the goalkeeper (SC); 4) shots that result in rebounds with defense ball possession (SRDP); 5) shots that result in rebounds with attack ball possession (SRAP); 6) shots blocked with defense ball possession (SBPD); and 7) shots blocked with attack ball possession (SBAP). Neuropsychological measures: omission errors on the CPT-II (OE); commission errors on the CPT-II (COE); total score from IGT (net score). The $r$ values refer to original data and the $p$ values refer to the 1000 resampling.

Table 5 .

Correlations between performance measures and neuropsychological measures.

\begin{tabular}{|c|c|c|c|c|c|}
\hline \multirow{2}{*}{ Impulsivity measures } & & \multicolumn{4}{|c|}{ Other performance measures } \\
\hline & & GPB & PAS & $\mathrm{FC}$ & FS \\
\hline \multirow[t]{2}{*}{$\mathrm{OE}$} & $r=$ & $-.63 *$ & .28 & $-.63 *$ & $-.62 *$ \\
\hline & $p=$ & .03 & .41 & .04 & .02 \\
\hline \multirow[t]{2}{*}{ COE } & $r=$ & -.11 & -.13 & -.29 & -.52 \\
\hline & $p=$ & .73 & .66 & .37 & .10 \\
\hline \multirow[t]{2}{*}{ Net Score } & $r=$ & .18 & .05 & .28 & .27 \\
\hline & $p=$ & .59 & .84 & .39 & .41 \\
\hline
\end{tabular}

Note: "significant correlation ( $\mathrm{p} \leq .05$ ). Technical performance measures: 1) gaining possession of the ball (GPB); 2) passive play (PASSIV); 3 ) fouls committed (FC); and 4) fouls suffered (FS). Neuropsychological measures: OE $=$ omission errors on the CPT-II; COE $=$ commission errors on the CPT-II; net score $=$ total score on the IGT. The $r$ values refer to original data and the $p$ values refer to the 1000 resampling.

required. One possible way to investigate this directly is to administer the Functional Impulsivity Scale (Dickman, 1990) to the players.

The attentional impulsivity analyses revealed a negative correlation between the omission errors on the CPT-II and several situations in which the player had some kind of contact with the opponent. High numbers of fouls suffered (committed or offensive) were related to low attentional impulsivity. One could say that these findings also seem intuitively paradoxical. However, because a person with a high level of attentional impulsivity presents an inability to focus on a task (Malloy-Diniz et al., 2007)_perhaps resulting from a greater susceptibility to changes in arousal (Stanford et al., 2009) - it is possible that he or she has more restricted participation during matches due to his or her higher distractibility. This type of behavior would explain the inverse correlation found between attentional impulsivity and fouls, as highly impulsive players are those less involved in contact situations. Taking into account the limitations of correlational studies and the lack of previous research with similar characteristics, this assumption should be viewed cautiously.

Attentional impulsivity also showed a negative correlation with the gaining possession of the ball measure. Here, the results seem intuitive: low levels of attentional impulsivity were related to higher numbers of "stolen" balls. In this case, players who were more focused on their tasks probably had more success in this technical fundament.

A positive correlation was found between rebounds with defense ball possession and motor impulsivity. Here, it is possible that 1) a trend to specify stereotyped motor responses or 2) a propensity to respond rapidly, thereby emphasizing the speed to the detriment had some influence in this finding. Spinella (2005) found that motor impulsivity is related to deficits in self-inhibition. It is possible that an inability to inhibit pre-potent motor responses, observed in high-impulsive subjects (Möller et al., 2001), creates more a stereotyped pattern of throwing that facilitates the action of the goalkeepers. Another explanation is related to the speed-accuracy trade-off phenomenon (Schmidt \& Lee, 2005). This phenomenon is associated to the human tendency to decrease the accuracy of a motor response when its speed is increased. Literature about impulsivity shows that high-impulsive subjects are faster in their responses but less accurate than their less impulsive counterparts (Lage et al., in press). Therefore, it is possible that high-impulsive players presented faster throwing, but with a decreased accuracy when compared to the low-impulsives, characteristic that facilitates the action of the goalkeepers.

In short, this study is the first to produce evidence of a relationship between impulsivity and technical performance in an open-skill sport. As a consequence, this study may open a 
promising way of investigating the impact of impulsivity in a specific context of sportive performance. However, it is important to remember that the need for a resampling statistical approach only allowed us to draw assumptions about the sample at hand, rather than about the population as a whole (Stergiou, 2004). Furthermore, the descriptive analysis does not prove any causal relationship between impulsivity and performance. Due to these limitations, our results should be interpreted with caution. Further studies with a sample size that permits the separation of high impulsivity athletes from low impulsivity athletes are needed in order to compare the technical performance between the two groups. Similar investigations with other openskill sports are also suggested.

\section{Acknowledgements}

This work was supported by FAPEMIG, FUNADESP and ProPIC FUMEC.

\section{References}

Barrat, E. S. (1981). Time perception, cortical evoked potentials and impulsiveness among three groups of adolescents. In J. K. Hays, T. K. Roberts, \& K. S. Solway (Eds.), Violence and the violent individual (pp. 87-95). New York: Spectrum Publications.

Bechara, A., \& Van Der Linden, M. (2005). Decision-making and impulse control after frontal lobe injuries. Current Opinion in Neurology, 18, 734-739. doi:10.1097/01.wco.0000194141.56429.3c

Dickman, S. (1990). Functional and dysfunctional impulsivity: Personality and cognitive correlates. Journal of Personality and Social Psychology, 58, 95-102. doi:10.1037/0022-3514.58.1.95

Dickman, S. (1993). Impulsivity and information processing. In W. Mccown, M. Shure, \& J. Johnson (Eds.), The impulsive client: Theory, research and treatment (pp. 151-184). Washington, DC: American Psychological Association. doi:10.1037/10500-010

Dickman, S. J., \& Meyer, D. E. (1988). Impulsivity and speed-accuracy tradeoffs in information processing. Journal of Personality and Social Psychology, 54, 274-290. doi:10.1037/0022-3514.54.2.274

Edgington, E. S., \& Onghena, P. (2007). Randomization tests (4th ed.). Boca Raton, FL: Chapman \& Hall/CRC.

Enticott, P. G., Ogloff, R. P., \& Bradshaw, J. (2006). Associations between laboratory measures of executive inhibitory control and selfreported impulsivity. Personality and Individual Differences, 41, 285-294. doi:10.1016/j.paid.2006.01.011

Expósito, J., \& Andrés-Pueyo, A. (1997). The effects of impulsivity on the perceptual and decision stages in a choice reaction time task. Personality and Individual Differences, 22, 693-697. doi:10.1016/S0191-8869(96)00259-0

Lage, G. M., Malloy-Diniz, L. F., Matos, L. O., Bastos, M. A. R.,
Abrantes, S. S., \& Corrêa, H. (2010). Impulsivity and the 5-HTTLPR polymorphism in a non-clinical sample. Plos One, 6, e16927. doi:10.1371/journal.pone.0016927

Lage, G. M., Malloy-Diniz, L. F., Neves, F. S., Moraes, P. H. P, Corrêa, $\mathrm{H}$. (in press). A kinematic analysis of the association between impulsivity and manual aiming. Human Movement Science.

Lemke, M. R., Fischer, C. J., Wendorff, T., Fritzer, G., Rupp, Z., \& Tetzlaff, S. (2005). Modulation of involuntary and voluntary behavior following emotional stimuli in healthy subjects. Progress in Neuro-Psychopharmacology and Biological Psychiatry, 29, 69-76. doi:10.1016/i.pnpbp.2004.10.007

Lijffijt, M., Bekker, E. M., Quik, E. H., Bakker, J., Kenemans, J. L., \& Verbaten, M. N. (2004). Differences between low and high trait impulsivity are not associated with differences in inhibitory motor control. Journal of Attention Disorders, 8, 25-32. doi: $10.1177 / 108705470400800104$

Malloy-Diniz, L. F., Fuentes, D., Leite, W. B. Correa, H., \& Bechara, A. (2007). Impulsive behavior in adults with ADHD: Characterization of motor, attentional and cognitive impulsiveness. Journal of the International Neuropsychological Society, 13, 693-698. doi:10.1017/S1355617707070889

Möller, F. G., Barrat, E. S., Dougherty, D. M., Schmitz, J. M., \& Swann, A. C. (2001). Psychiatry aspects of impulsivity. American Journal of Psychiatry, 158, 1783-1793. doi:10.1176/appi.ajp.158.11.1783

Patton, J. H., Stanford, M. S., \& Barrat, E. S. (1995). Factor structure of the barratt impulsiveness scale. Journal of Clinical Psychology, 51, 768-774. doi:10.1002/1097-4679(199511)51:6<768::AID-JCLP2270510607> 3.0.CO;2-1

Reeve, C. L. (2007). Functional impulsivity and speeded ability test performance. International Journal of Selection and Assessment, 15, 56-62. doi:10.1111/j.1468-2389.2007.00367.x

Ripoll, H., Kerlirzin, Y., Stein, J., \& Reine, B. (1995). Analysis of information processing, decision making, and visual strategies in complex problem solving sport situations. Human Movement Science, 14, 325-349. doi:10.1016/0167-9457(95)00019-O

Schmidt, R. A., \& Lee, T. D. (1999). Motor control and learning: A behavioral emphasis (3rd ed.). Champaign: Human Kinetics.

Spinella, M. (2005). Prefrontal substrates of empathy: Psychometric evidence in a community sample. Biological Psychology, 70, 175181. doi:10.1016/j.biopsycho.2004.01.005

Stergiou, N. (2004). Innovative analyses of human movement. Champaign, Il: Human Kinetics.

Stanford, M. S., Mathias, C. W., Dougherty, D. M., Lake, S. L., Anderson, N. E., \& Patton, J. H. (2009). Fifty years of the barratt impulsiveness scale: An update and review. Personality and Individual Differences, 47, 385-395

Svebak, S., \& Kerr, J. (1989). The role of impulsivity in preference for sports. Personality and Individual Differences, 10, 51-58. doi:10.1016/0191-8869(89)90177-3

Vieira, M. V. G., Greco, P. J., \& Chagas, M. H. (1990). Scientific proposal for assessment of handball games. Revista Kinesis, 6, 163-185. 